\title{
Partial migration in fishes: definitions, methodologies and taxonomic distribution
}

\author{
B. B. Chapman*†, C. Skov $\$$, K. Hulthén*, J. Brodersen*\$, \\ P. A. NilsSON*, L.-A. HANSSON* AND C. BRÖNMARK* \\ *Department of Biology, Lund University, Ecology Building, Solvegatan 37, 22362 Lund, \\ Sweden and $\$$ National Institute of Aquatic Resources, Technical University of Denmark \\ (DTU), Vejlsøvej 39, 8600 Silkeborg, Denmark
}

\begin{abstract}
Partial migration, where populations are composed of both migratory and resident individuals, is extremely widespread across the animal kingdom. Researchers studying fish movements have long recognized that many fishes are partial migrants, however, no detailed taxonomic review has ever been published. In addition, previous work and synthesis has been hampered by a varied lexicon associated with this phenomenon in fishes. In this review, definitions and important concepts in partial migration research are discussed, and a classification system of the different forms of partial migration in fishes introduced. Next, a detailed taxonomic overview of partial migration in this group is considered. Finally, methodological approaches that ichthyologists can use to study this fascinating phenomenon are reviewed. Partial migration is more widespread amongst fishes than previously thought, and given the array of techniques available to fish biologists to study migratory variation the future of the field looks promising.

(C) 2012 The Authors

Journal of Fish Biology (c) 2012 The Fisheries Society of the British Isles
\end{abstract}

Key words: anadromy; catadromy; fish migration; life history diversity; telemetry.

\section{INTRODUCTION}

The importance of animal migration is reflected in its long history of study by biologists. Bird migration has received the most research effort, most likely due to the conspicuous seasonal presence and absence of many bird species, and the relative ease of marking and observing individuals. Yet migration is extremely widespread and has been documented in a diverse range of taxa, from wildebeest to whales, and from water fleas to fishes (Chapman et al., 2011a). Of all the migratory animals, the migration of fishes is perhaps the most enigmatic. Fish migration is difficult to observe, and individuals can be very difficult to track as they migrate often vast distances beneath the water's surface. As technology has advanced and the capacity to follow the movements of individuals has improved, the sheer diversity of

†Author to whom correspondence should be addressed. Tel.: +46 736643 608; email: ben.chapman@ biol.lu.se

§Present address: Department of Fish Ecology and Evolution, EAWAG Swiss Federal Institute of Aquatic Science and Technology, Center of Ecology, Evolution and Biochemistry, Seestrasse 79, CH-6047 Kastanienbaum, Switzerland 
migratory behaviour in fishes has become apparent. A remarkable range of migratory behaviours occur in nature, varying from the daily vertical movements of coregonids (Mehner \& Kasprzak, 2011) and the short-distance migration of cyprinids in and out of shallow lakes (Skov et al., 2008) to the vast oceanic journeys of Atlantic bluefin tuna Thunnus thynnus (L. 1758) (Block et al., 2005). Migratory patterns can also vary between populations and even among individuals within populations. Such intraspecific variation in migratory behaviour is extremely widespread, and appears to be the rule rather than the exception (Newton, 2008; Chapman et al., 2011b). Fish from different populations can vary in their likelihood of migrating, or in the distance they migrate and also in the migratory destination. For example, brown trout Salmo trutta L. 1758 can have populations composed entirely of anadromous migrants or entirely of freshwater residents (Bohlin et al., 2001). Yet perhaps the most intriguing intraspecific variation can be found within populations. In a growing number of examples, individuals from the same population show differences in migratory behaviour, with some migrating on seasonal or diel time scales between habitats whilst others remain resident in a single habitat (Dingle, 1996). This withinpopulation migratory dimorphism is known as partial migration and is ubiquitous amongst migratory taxa, with many examples of partially migratory invertebrates, fishes, birds and mammals documented in the wild (Hansson \& Hylander, 2009; Boyle, 2011; Cagnacci et al., 2011; Grayson et al., 2011).

The most recent review of partial migration in fishes describes just 11 species as exhibiting partial migration (Jonsson \& Jonsson, 1993), and of these, seven were salmonids. Advances in techniques to study fish migration in the past two decades, however, have revealed how taxonomically widespread partial migration is amongst fishes. One of the factors that has masked the prevalence of this type of migration in fishes in the past is that partial migration has a varied lexicon, with many researchers using different terms to describe the same kinds of migratory behaviours (Secor $\&$ Kerr, 2009). Here, definitions and fundamental concepts in partial migration are reviewed, followed by an updated taxonomic overview of this phenomenon in fishes. The review closes with a discussion of the techniques that can be used to study partial migration. The aims of this review are to (1) suggest a unified series of terminology to stimulate research and promote understanding between ichthyologists of different backgrounds, (2) demonstrate the taxonomic breadth and hence general importance of partial migration for fishes, and finally (3) give a brief introduction to the methods currently employed to collect data on partial migration in fishes. Throughout the review terminology from both migration biologists and also fisheries scientists is adopted in the hope that by doing so interactions between researchers from these different fields can be encouraged and future semantic confusion avoided (Table I). A second paper in this thematic addresses the causes and consequences of partial migration in fishes (Chapman et al., 2012).

Upon reviewing the literature it is clear that the study of partial migration in fishes is in its infancy. Research has been taxonomically skewed to certain groups, so much more is known about salmonid partial migration (Jonsson \& Jonsson, 1993; Hendry et al., 2004) but very little about partial migration in other fishes [although there are a growing number of studies into cyprinid partial migration (Brodersen et al., 2008a; Skov et al., 2010; Chapman et al., 2011c)]. In particular partial migration has received little attention for marine fishes (i.e. oceanodromous migrants) and also Neotropical and African species. 
TABLE I. A lexicon of partial migration in fishes

Anadromy: a widespread migratory life history in fishes where spawning occurs in fresh water and individuals migrate to the sea as juveniles and adults.

Catadromy: a type of migration where fish spawn in marine habitats and migrate to freshwater as juveniles and adults.

Contingent: a term to collectively describe groups of migratory or resident individuals within a partially migratory population (Secor 1999). Hence a partially migratory population is composed of a migratory contingent and a resident contingent. Note that this does not necessarily imply that migratory status is fixed for individual fishes (Chapman et al., 2012).

Diel vertical migration (DVM): a behaviour often documented in pelagic oceanic or lake-dwelling fishes, where individuals migrate from the deep waters to the epipelagic waters. Usually DVM is on a diurnal timescale, with vertical migration to the epipelagic occurring at night.

Life-history polymorphism or diversity (also alternative life history strategies, life cycle diversity): these are general terms to describe intraspecific variation in life history strategies.They are non-specific, however, and can refer to various forms of non-migratory life-history variation (for example alternative reproductive strategies).

Migrant: a migratory individual; a member of a migratory contingent. Other terminology has been used in previous studies (e.g. disperser, ocean type and stray).

Oceanodromy: migration between marine habitats.

Partial anadromy: a form of partial migration where the migratory contingent move from fresh water to the sea, returning to spawn, whilst residents remain in fresh water for the entire cycle (partial catadromy is this situation reversed, i.e. residents remain all year round in the marine environment).

Partial migration: a prevalent form of animal migration, which occurs when a population contains both migratory and resident individuals.

Potamodromy: migration between freshwater habitats, e.g. migration from adult habitat in lakes to spawning habitats in streams.

Resident: a term to describe an individual within a partially migratory population that does not make migratory movements (also referred to as retentive or sedentary).

Semi-anadromy: migration from fresh water to brackish (e.g. estuarine) habitats.

\section{DEFINING AND CATEGORIZING PARTIAL MIGRATION IN FISHES}

Partial migration describes the phenomenon where a population consists of both migratory and resident individuals. Therefore any population with between 1 and $99 \%$ migrants can be considered to be a partially migratory population. It is likely that many migratory fish populations are in fact partially migratory. For example, even in species such as T. thynnus, which is often used to exemplify long distance aquatic migration, some individuals may remain resident around the spawning grounds throughout the entire year (Baker, 1978). Especially in fishes, progress in understanding patterns of partial migration has been hampered by variation in terminology for different species, however, many recent studies into partial migration have begun to overcome this, with studies into perciformes (Kerr \& Secor, 2010), cypriniformes (Chapman et al., 2011c) and salmoniformes (Olsson et al., 2006) using similar terminology to investigate this phenomenon (which is also adopted here and integrated into the broader fisheries terminology: see Table I). 

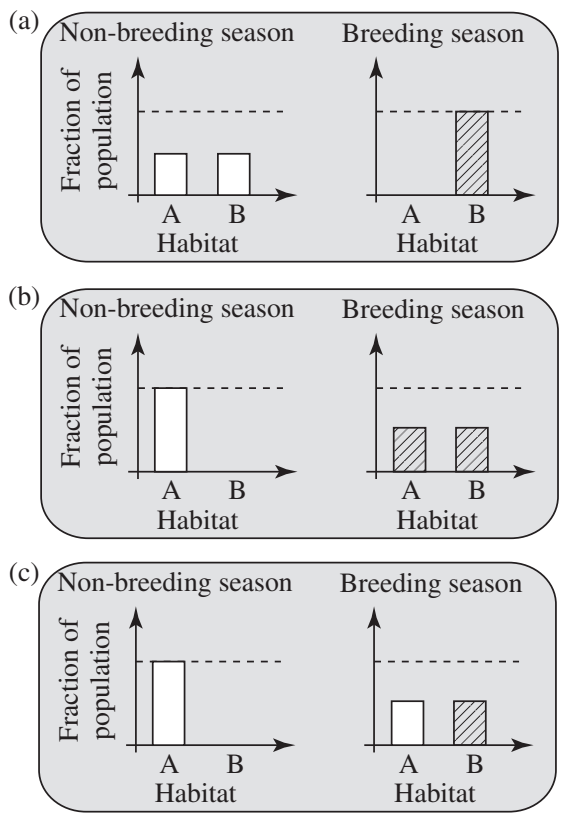

FIG. 1. Schematic of three different types of seasonal partial migration: (a) non-breeding partial migration: residents and migrants share a breeding habitat but spend the non-breeding season apart, (b) breeding partial migration: residents and migrants share a non-breeding habitat and breed apart, and (c) skipped breeding partial migration where residents and migrants are apart during the breeding season, but as migration is required for reproduction only migrant individuals reproduce. Each panel shows the fraction of the population in each of the two habitats (A and B) during each of two seasons (non-breeding and breeding). $\square$, individuals that are reproducing. Reproduced with permission from Shaw \& Levin (2011).

Three types of seasonal partial migration have been commonly described in the literature (Chapman et al., 2011b; Fig. 1): (1) migrants and residents breed sympatrically, but overwinter apart (e.g. three-spined sticklebacks Gasterosteus aculeatus L. 1758 Kitamura et al., 2006). This form of partial migration is in a sense the classic form of partial migration. This is referred to as non-breeding partial migration [Fig. 1(a)]; (2) migrants and residents overwinter together whereas they breed allopatrically [e.g. pike Esox lucius L. 1758 (Engstedt et al., 2011)]. This is referred to as breeding partial migration [Fig. 1(b)]; (3) individuals migrate to breed, but not every year (Rideout et al., 2005) leading to partial migration [e.g. shortnose sturgeon Acipenser brevirostrum LeSueur 1818 (Dadswell, 1979)]. This form of partial migration, where some individuals forgo breeding each year and hence forgo migration, has rarely been considered in the partial migration literature until recently (Shaw \& Levin, 2011). Despite this it appears to be widespread in fishes, especially in oceanodromous species and species that make long and costly migrations to spawn. This is referred to as skipped breeding partial migration [Fig. 1(c)].

In addition, a fourth form of partial migration can be recognised, which occurs over shorter temporal and spatial scales: (4) Partial diel vertical migration (DVM): some individuals migrate vertically (usually at night) whilst others remain at the same place in the water column. This has been noted in a number of fish species, including coregonids (Mehner \& Kasprzak, 2011) and Bear Lake sculpin Cottus 
extensus Bailey \& Bond 1963 (Neverman \& Wurtsbaugh, 1994). This is referred to as partial DVM.

Classically, partial migration has been considered in the context of avian migration, where populations of birds can be relatively well defined. For many fishes, especially oceanic species, however, populations can range across vast areas of habitat, and so partial migration at a scale relevant to the particular species in question must be considered. Additionally, often fishes will undertake substantial journeys from nursery areas to adult habitats and it is upon reaching these habitats that some individuals migrate from and some remain resident [e.g. European eels Anguilla anguilla (L. 1758) (Tsukamoto et al., 1998)]. In this example all individuals are in a sense migratory (as they migrate as larvae from the spawning grounds and return as adults to breed), but within a specific life stage only part of the population will migrate. Here, an inclusive approach is taken and migratory polymorphism within a particular life stage is also defined as partial migration, even when all individuals have migrated as larvae. It is of note that the categories of partial migration described above are not necessarily mutually exclusive of one another. For example, consider a case whereby a migratory contingent of fishes moves between two spatially segregated resident contingents $\mathrm{A}$ and $\mathrm{B}$, feeding at site $\mathrm{A}$ and spawning at site $\mathrm{B}$. These migrants could thereby be classed as breeding partial migrants when related to site A residents and non-breeding partial migrants when related to site B residents. Such a case exists for herring Clupea harengus L. 1758 populations which can be classified as displaying both breeding and non-breeding partial migration, depending upon the perspective (Ruzzante et al., 2006). In addition, mature $C$. harengus do not migrate to spawn each year [skipped breeding partial migration (Engelhard \& Heino, 2005)]. Finally, young-of-the-year (YOY) C. harengus also display a bimodal vertical distribution and can hence also be classified as exhibiting partial DVM (Jensen et al., 2011). This example highlights the complexity evident in migratory and movement patterns in fishes in the wild, which (unfortunately for ichthyologists) defies neat and exclusive categorization.

\section{PARTIAL MIGRATION IN FISHES: A TAXONOMIC OVERVIEW}

Partial migration has now been documented in a remarkably wide range of fishes, and has been described for all major types of migratory behaviour (anadromy, catadromy, oceanodromy and potamodromy). In this section some of the many examples of partial migration in fishes in the wild are described. The goal here is not to provide an exhaustive list of partially migratory fishes, but rather to highlight how taxonomically widespread intrapopulation migratory diversity is by giving examples of species from the many different orders that exhibit partial migration.

\section{ANGUILLIFORMES}

Until relatively recently, freshwater anguillid eels were synonymous with obligate catadromy, whereby mature adults migrate from freshwater habitats to spawn in the sea. A landmark study, however, showed that A. anguilla are actually composed of two distinct migratory contingents: the first with individuals that make the catadromous journey from marine to fresh water (migrants) and the second with 
individuals that never migrate into fresh water but spend their whole lives in the sea [marine residents (Tsukamoto et al., 1998)]. Other species of eel have since been shown to display similar patterns of partial migration, including the Japanese eel Anguilla japonica Temminck \& Schlegel 1846 and American eel Anguilla rostrata (LeSueur 1817) (Daverat et al., 2006), and also a tropical species, the Indonesian shortfin eel Anguilla bicolor bicolor McClelland 1844 (Chino \& Arai, 2010).

\section{ACIPENSERIFORMES}

There are a number of examples of breeding partial migration in the sturgeon order. Male A. brevirostrum make spawning migrations just one out of every two years (Dadswell, 1979), and female Atlantic sturgeon Acipenser oxyrinchus Mitchill 1814 breed just once every 2-5 years (Smith 1985). No reports of other forms of migratory dimorphism in this group, however, could be found.

\section{BERCIFORMES}

This order is composed of mostly deep-sea fishes and is poorly studied. The orange roughy Hoplostethus atlanticus Collett 1889 is a bathypelagic marine fish which makes oceanodromous spawning migrations. Not all individuals in a population, however, breed each year [skipped breeding partial migration (Bell et al., 1992)].

\section{CHARACIFORMES}

The migratory behaviour of characiformes is not well understood at an individual level, partly as this group is prevalent in the Neotropics and Africa where information about fish migration is scarce. Studies of two species, however, are suggestive of different forms of partial migration in this group. Populations of the coporo Prochilodus mariae Eigenmann 1922 are composed of both migratory and resident individuals, with some individuals migrating from lagoons into rivers following the breeding season [non-breeding partial migration (Saldana \& Venables, 1983)]. Furthermore, a recent study of a fish from the same genus, the zulega Prochilodus argenteus Spix \& Agassiz 1829, a freshwater fish found in Brazilian rivers, showed that this species is a potamodromous partial migrant. Twenty-one \% of tagged individuals remained resident within a limited area and the remainder migrated to spawn [breeding partial migration (Godinho \& Kynard, 2006)].

\section{CLUPEIFORMES}

This order includes many economically important food species from the herring and anchovy families. There have been a number of reports of partial migration from this group, including C. harengus, blueback herring Alosa aestivalis (Mitchill 1814) and tapertail anchovy Colia mystus (L. 1758). For example, molecular analysis of $C$. harengus, from the North Sea and adjacent areas revealed that there were genetic differences between fish from three regions (Ruzzante et al., 2006). Clupea harengus, from these regional contingents share common feeding grounds but migrate to spawn in distinct areas [breeding partial migration (Ruzzante et al., 2006)], with some fish remaining resident in a single region to feed and spawn whilst others migrated to spawn in a different region. Clupea harengus are thought to exhibit 
strong natal homing to spawning grounds (Iles \& Sinclair, 1982), and this factor may be important in breeding partial migration if good feeding grounds are not patchily distributed. Additional reports analysing otolith annuli shape suggest that the Celtic Sea $C$. harengus population is also partially migratory, with the migratory contingent moving into the Irish Sea. In this population, migrants grow more slowly and hence recruit later to the adult population than residents (Burke et al., 2008). Further evidence from scale analysis shows that herring may skip breeding migrations in certain years (Engelhard \& Heino, 2005). The YOY C. harengus also exhibit partial DVM (Jensen et al., 2011).

In anadromous A. aestivalis, recent analysis using otolith microchemistry to infer patterns of migration between freshwater habitats and the sea showed evidence for a small (c. 4\%) resident contingent for this species (Limburg et al., 2001). A similar analysis for anadromous C. mystus from the Changjiang Estuary in China also revealed that freshwater residents exist in this species, which was previously thought to be entirely anadromous (Yang et al., 2006).

\section{CYPRINIFORMES}

A recent increase in research effort into cyprinid partial migration means that this group of fishes is probably the best studied example of potamodromous partial migration available (Jepsen \& Berg, 2002; Brodersen et al., 2008a, 2011, 2012; Brönmark et al., 2008; Skov et al., 2008, 2010, 2011; Chapman et al., 2011c). Various cyprinid species partially migrate out of shallow lakes into connecting streams over winter (non-breeding partial migration). In a study in a Swedish lake, Lake Krankesjön, patterns of cyprinid partial migration in roach Rutilus rutilus (L. 1758), white bream Blicca bjorkna (L. 1758) and rudd Scardinius erythrophthalmus (L. 1758). All three species exhibited partial migration, with $55 \%$ of tagged B. bjorkna, $40 \%$ of $R$. rutilus and $5 \%$ of S. erythrophthalmus migrating (Skov et al., 2008). Rutilus rutilus and B. bjorkna mostly migrated overwinter, with a second peak in the spring, whilst the few $S$. erythrophthalmus that migrated did so in spring. The migratory behaviour of this particular population of $R$. rutilus has now been studied intensively for almost a decade, and it is clear that the proportion of migrants varies substantially between years (Brodersen et al., 2011). Migrant $R$. rutilus show consistency both in terms of site fidelity and the timing of migration (Brodersen et al., 2012), and also migratory status (B. B. Chapman unpubli. data). This case of partial migration has also been shown to have considerable effects on the lake ecosystem, for example by influencing the zooplankton population dynamics (Hansson et al., 2007) or potentially the dynamics of the entire system (Brönmark et al., 2010). Partial migration has also been documented in the common bream Abramis brama (L. 1758) in a study in two Danish lakes (Skov et al., 2011). The evidence here is strongly suggestive that $A$. brama (partially) migrate from shallow lakes into the surrounding streams overwinter to refuge from piscivorous predators such as E. lucius. Predation risk has been implicated as playing an important role in the migratory dynamics of a number of fish species (Chapman et al., 2012).

\section{ELASMOBRANCHII}

There are a number of reports that spiny dogfish Squalus acanthias L. 1758 populations are partially migratory. Whilst around $90 \%$ of the S. acanthias caught 
and tagged in the waters around Newfoundland were recovered in the same region, the remaining 10\% were recaptured much further afield, in the Gulf of St Lawrence, Nova Scotia and U.S. waters (Campana et al., 2009). These patterns, along with data from a north-east Pacific Ocean population, where $85 \%$ remained resident, are strongly suggestive of partial migration in this species (McFarlane \& King, 2003). Some sharks perform skipped breeding partial migrations, for example the Australian school shark Galeorhinus australis Macleay 1881 (Olsen, 1954; in Shaw \& Levin, 2011). Whilst evidence to suggest that other elasmobranchs engage in breeding or non-breeding partial migrations is lacking, there are some candidate species that deserve further attention. Euryhaline bull sharks Carcharhinus leucas (Müller \& Henle 1839) that were studied in an early tagging project were found to have contingents that migrate from the Caribbean Sea into Lake Nicaragua (Thorson, 1971). Little is known, however, about the periodicity of these movements or what proportion of the population makes these catadromous forays from the sea into lakes.

\section{ESOCIFORMES}

Lake dwelling E. lucius have been shown to partially migrate into connected streams in very low numbers during spring in a study by Skov et al. (2008). Thus, freshwater E. lucius potentially partake in a breeding partial migration, although the evidence here is scarce and further studies are required. Observations of large $E$. lucius in the streams in spring around the same lake over recent years also support this idea (B. B. Chapman pers. obs.). Esox lucius have partially migratory populations that inhabit brackish environments such as the Baltic Sea. These populations are composed of resident individuals that spawn in the bays of the Baltic Sea and of migrants that swim into freshwater habitats to spawn [breeding partial migration (Engstedt et al., 2011)].

\section{GADIFORMES}

The gadiformes are mostly marine fishes that comprise a number of food fishes, including the Atlantic cod Gadus morhua L. 1758. Gadus morhua are an exceptionally important commercial species and a number of studies suggest that some populations are partially migratory. For example, acoustic telemetry research into the movements and habitat use of juvenile (age $2-3$ year) G. morhua in a Newfoundland fjord showed that $c .70 \%$ from this age class made winter migrations to deeper waters, whilst 30\% remained resident (Cote et al., 2004). Migrant G. morhua were in better condition than resident fish, which suggests that residency could be a best-of-a-bad-job strategy for individuals that cannot pay the energetic costs associated with migration. Others have also reported similar proportions of migrants and residents for this species (Comeau et al., 2002). Sympatric G. morhua can also display striking colour variation. For example, an offshore population in the Gulf of Maine comprises two colour variants, with red and olive-coloured fish inhabiting the same area. A recent study showed that colouration correlated with body shape, and the authors suggest that the two different colour morphs (which differ in their diet), represent different migratory contingents, with both residents (red fish) and migrants (olive fish) coexisting in sympatry (Sherwood \& Grabowski, 2010). Further research on this interesting system will clarify whether the partial migration hypothesis holds for red and olive G. morhua in the Gulf of Maine. 


\section{GASTEROSTIFORMES}

Gasterosteus aculeatus inhabits many different habitats, from freshwater ponds and streams to brackish estuaries and coastal marine environments. The Pacific Ocean form of this species is composed of both anadromous migratory and freshwater resident individuals. These groups differ morphologically but allozyme analysis suggests that they form a single breeding population (Higuchi et al., 1996). A study of juvenile G. aculeatus from a nursery pond in Hokkaido, Japan, showed that fish from this population contained both resident individuals and also anadromous migrants [non-breeding partial migration (Kitamura et al., 2006)]. Furthermore, the authors show that smaller juveniles adopt the migratory strategy. A second study is suggestive of breeding partial migration in this species. Kedney et al. (1987) reported that G. aculeatus in the St Lawrence Estuary comprised both anadromous fish that migrated to spawn in fresh water and estuarine residents.

\section{MYCTOPHIFORMES}

This order is composed of deep-sea fishes that mostly belong to the lanternfish family, Myctophidae. In one species in this family, the northern lampfish Stenobrachius leucopsarus (Eigenmann \& Eigenmann 1890), a bimodal distribution of fish was documented at night. The first peak of abundance occurred at $100 \mathrm{~m}$ depth, and the second at 300-500 m depth [partial DVM (Pearcy et al., 1979)]. Other studies also suggest that partial DVM is common in this group, and occurs in other myctophids besides S. leucopsarus (Pearcy et al., 1979).

\section{OSMERIFORMES}

There are scattered reports of potential migratory dimorphism in the smelts, all of which are suggestive of partial migration (more specifically partial anadromy), and all of which require more study. The New Zealand smelt Retropinna retropinna (Richardson 1848) has been shown to have two distinct morphological types, which have been inferred to be river migratory (anadromous) and lake resident forms (Northcote \& Ward, 1984). These ecotypes show a bimodal distribution for many meristic characteristics, and differ in gill raker and vertebral number in addition to mass and length relationships and fecundity measurements. Circumstantial evidence is presented that bimodal morphological distributions for gill raker and vertebral counts are only present in open lowland lakes, and not in closed lakes, rivers or coastal waters (Northcote et al., 1992). Isotope studies to investigate whether this species is partially anadromous, however, have been inconclusive and so a conclusive assessment of partial migration in this species is not possible. Another stable isotope study based in New Zealand showed that a species previously considered to be diadromous, the koaro Galaxias brevipinnis Günther 1866, contained fish that had never migrated to sea (Hicks et al., 2005). Again, this study is suggestive of partial migration, however, it is difficult to conclude this on the basis of a study with such a low sample size $(n=6$, with just a single individual showing no microchemical signature of sea migration). The wasagi (ice-fish) Hypomesus nipponensis McAllister 1963 has also been reported to exhibit partial migration, with anadromous and freshwater resident forms coexisting (Arai et al., 2006). Populations of H. nipponensis are also composed of estuarine residents that do not enter freshwater 
habitats, highlighting the diversity of life history strategies in this species. A final example of an osmerid partial migrant is the shiraou Salangichthys microdon (Bleeker 1860), an important species in eastern Asian fisheries. Stable-isotope analysis of S. microdon from Hokkaido, Japan, indicate that this lake population are partially migratory, with the majority of fish exhibiting anadromous behaviour and a minority (c. 15\%) remaining as lacustrine residents (Arai et al., 2003).

\section{PERCIFORMES}

There are many diverse examples of partial migration amongst perciformes, but most studies simply document that migratory and resident contingents occur. One exception to this is white perch Morone americana (Gmelin 1789), which has been the focus of detailed research in recent years. Morone americana partially migrate from their natal freshwater habitats into brackish estuaries in North America (Kerr \& Secor, 2011), with the majority of fish (>90\%) migrating (Kerr et al., 2009). These alternative life history strategies are influenced by early life conditions, with early spawned larval cohorts making up the majority of the migratory contingent (Kerr \& Secor, 2010). Early spawned fish had low growth rates compared to late spawned fish, most likely due to temporal variation in food (zooplankton) abundance (Kerr \& Secor, 2010). Striped bass Morone saxatilis (Walbaum 1792) have also been shown to have a variety of migratory modes within populations (Secor et al., 2001). In this species, as with many other partially anadromous fishes, males dominated the resident contingent, and females the oceanic migratory contingent. Dorsal colouration in this species has also been linked to migratory strategy, with black dorsal colouration for freshwater residents and green for oceanic migrants (Paramore \& Rulifson, 2001).

Perch Perca fluviatus L. 1758 populations have also been observed making partial migrations out of shallow lakes in Northern Europe (Skov et al., 2008), and the proportion of migrants varies significantly between lakes (C. Skov, unpubli. data). In marine fishes there is some evidence for partial migration in oceanodromous perciformes such as spotnape cardinalfish Apogon notatus (Houttuyn 1782) and $T$. thynnus. Apogon notatus are found in the coastal waters of the north-western Pacific Ocean. They spawn in neritic breeding grounds, and most migrate overwinter into deeper waters, whilst some remain resident (Fukumori et al., 2008). Finally for this group, T. thynnus have been reported as potentially exhibiting patterns similar to partial migration [non-breeding partial migration (Baker, 1978)]. Following spawning in the Mediterranean Sea, some fish remain in this area whilst others migrate out into the Atlantic Ocean, migrating northwards to Norway and making a return journey during winter. These inferences are based on an old study which used the identification of fishermen's hooks from different regions to study T. thynnus migration (Sella, 1930). More recent work which is currently in progress using modern tagging techniques, however, suggests that the classification of the Mediterranean population of T. thynnus as partial migrants may indeed be accurate (J. M. Fromentin pers. comm.). Furthermore, geoposition data from 330 electronically tagged T. thynnus shows that fish tagged in the western Atlantic Ocean have overlapping foraging grounds in the North Atlantic Ocean but form two geographically distinct breeding groups, with individuals migrating to spawn in the Mediterranean Sea and the Gulf of Mexico [breeding partial migration (Block et al., 2005)]. 


\section{PETROMYZONTIFORMES}

This order comprises entirely of lamprey, which are one of the most ancient and successful orders of living fishes. Whether or not lamprey are partial migrants cannot currently be concluded, as this is still a topic of debate. Most genera of lamprey include species pairs of parasitic anadromous lamprey and freshwater nonparasitic residents (Zanandrea, 1959). During the juvenile stage the larvae of the two species are morphologically similar but the adults adopt different life-history strategies. Furthermore, species pairs have sympatric distributions, with freshwater residents being found within the distribution of parasitic anadromous lamprey (Hardisty, 1986). Given that it is now known how environmentally labile migratory strategy can be in fishes (Olsson et al., 2006), it seems plausible that the two putative species are actually distinct life-history forms within partially anadromous populations, such as has been documented in many other fishes. This idea is supported by the lack of genetic differentiation between species pairs. Some commentators (Salewski, 2003) suggest that this is because the species are very recently diverged whilst others (Schreiber \& Engelhorn, 1998) argue that this is supportive of the lifehistory dimorphism hypothesis. Currently the molecular evidence does not exclude either hypothesis (Espanhol et al., 2007), and so whether this is truly a case of partial anadromy remains to be seen.

\section{PLEURONECTIFORMES}

The flatfishes contain a number of commercially important marine species, including plaice Pleuronectes platessa L. 1758. A recent study into the stock structure of $P$. platessa is suggestive that some populations may be partially migratory. Based on data from $>2700$ tag recaptures of fish from populations on the west coast of England and Wales, Dunn \& Pawson (2002) describe a variety of movements from these fish. Their analysis of $P$. platessa tagged and released in the southeast Irish Sea suggests that some individuals dispersed to the Bristol Channel. Of the dispersed contingent, a small proportion remained resident in the Bristol Channel whilst the majority $(>70 \%)$ made feeding migrations to the Irish Sea (Dunn \& Pawson, 2002), which is suggestive of oceanodromous non-breeding partial migration in this species. Other potential partial migrants include starry flounder Platichthys stellatus (Pallas 1787), which is a coastal flatfish that spawns in sea water but juveniles can sometimes be found in rivers (Quinn \& Brodeur, 1991). Similarly, populations of European flounder Platichthys flesus (L. 1758) also display comparable patterns of facultative amphidromy, with freshwater migrants attaining a larger body size at age than marine residents (Beaumont \& Mann, 1984).

\section{SALMONIFORMES}

Amongst the fishes, the salmonids probably best exemplify migration in the public imagination. Many of the species in this group are extremely important to mankind, in both a cultural and commercial sense. The wealth of literature describing and analysing migratory patterns of salmonids makes reviewing such a body of work a daunting prospect, and so here the account is limited to providing a handful of examples of partial migration in this order, and direct interested readers to other more complete reviews (Jonsson \& Jonsson, 1993; Hendry et al., 2004). 
Many salmonids have partially anadromous populations containing both a resident freshwater contingent and a migratory marine contingent that spawn in the same area. For example, Oncorhynchus mykiss (Walbaum 1792) populations contain both resident rainbow trout and anadromous steelhead trout (McPhee et al., 2007). These divergent migratory strategies are thought to be a product of phenotypic plasticity (McPhee et al., 2007), however, recent evidence points to genetic differentiation between these forms (Pearse et al., 2009). One seemingly general pattern in the salmonids is that females dominate the migratory contingent (Jonsson \& Jonsson, 1993). This is likely because there is a positive relationship between body size and fecundity in female fishes, but not males, hence migrating to a highly productive marine environment can significantly increase reproductive capacity in this sex via an increase in growth rate relative to freshwater forms (Jonsson \& Jonsson, 1993). Males may also benefit from the greater body size associated with marine migration, as sexual selection is strong in many salmonids, both for female choice and also male-male competition. The costs of migration, however, are also considerable, potentially balancing fitness returns for migrants and residents (Chapman et al., 2012).

Potamodromous partial migrations have also been reported in this group. Arctic charr Salvelinus alpinus (L. 1758) that inhabit Lake Visjön in north-west Sweden contain lacustrine residents and also migrants that enter the streams in summer and make opportunistic feeding migrations to other lakes in the vicinity (Näslund et al., 1993). Similarly, S. trutta partially migrate from rivers to lakes (Olsson \& Greenburg, 2004).

Migratory salmonids have been reported skipping annual spawning migrations, most likely to conserve the energy costs of long distance migration to spawn in fresh water. Hence breeding partial migration is also evident in this group, for example in Atlantic salmon Salmo. salar L. 1758 (Schaffer \& Elson, 1975). Finally, fishes from the salmoniformes also exhibit partial DVM. Mapping of the vertical distribution of zooplanktivorous lake dwelling ciscoes Coregonus spp. in German lakes showed that some individuals migrate into the upper waters in the night, whilst others remain resident in the deep pelagic throughout the daily cycle (Mehner \& Kasprzak, 2011).

\section{SCORPAENIFORMES}

Whilst some species within this group show diverse migratory histories between populations [e.g. Japanese sculpin Cottus pollux Günther 1873 (Goto \& Arai, 2003)], varying from amphidromy to resident fluvial strategies, strong evidence for within population diversity (i.e. partial migration) is scarce. One species in this group which may potentially show partial migration, however, is sablefish Anoplopoma fimbria (Pallas 1814). Data from a tagging study carried out on this species were interpreted as showing that whilst the majority of fish remain resident, a minority travel much greater distances (Beamish \& McFarlane, 1988). Whether this is truly a case of partial migration, or whether the long distance movements were more akin to unidirectional dispersal remains to be seen.

Despite a lack of examples of seasonal partial migration, there is an example from this group of partial DVM. Juvenile C. extensus ( $<30 \mathrm{~mm}$ in standard length) carry out partial DVMs in American lakes, whilst larger fish remain resident in deeper waters (Neverman \& Wurtsbaugh, 1994). Laboratory trials suggest that this partial migration may be a strategy for smaller fish to increase their growth rate 
via increasing their digestion rate in the warmer surface waters (Neverman \& Wurtsbaugh, 1994).

\section{SILURIFORMES}

There is scant evidence that catfish species are partial migrants. A recent study of female piscivorous catfish, spotted sorubim Pseudoplatystoma corruscans (Spix \& Agassiz 1829), suggested that both migrant and resident behaviours were evident (Godinho et al., 2007). The authors state that migratory and resident fish were of similar size, and also that individuals can switch between strategies between different years, although data on these aspects were not presented.

\section{CURRENT TECHNIQUES IN PARTIAL MIGRATION STUDIES}

The primary goal of researchers who study migration is to understand when, where, why, and how animals migrate. Partial migration adds an additional dimension: who migrates? In some cases, such as many salmonids, migrants and residents differ phenotypically, and so identifying fish from different migratory contingents is relatively straightforward. In most other groups, however, morphological differences are either subtle or absent, and so other methods must be used to study partial migration. Information regarding which individuals migrate and also the timing and destination of migration can be collected in various ways, either directly or indirectly (Durbec et al., 2010). Direct information acquisition can occur by following individuals using some form of visible or electronic marker, or by visual encounters or hydroacoustics (Lucas \& Baras, 2001). Information can be indirectly gathered by deducing a fish's movements using natural, intrinsic biological or biogeochemical markers (Rubenstein \& Hobson, 2004). A range of different methods has been involved in studies of partial migration in fishes which are briefly reviewed here.

\section{DIRECT TECHNIQUES TO STUDY PARTIAL MIGRATION}

Telemetry is a common name for studies where some kind of electronic tag is placed internally or externally on the animal, after which the animal is followed over time and space with a resolution depending on the type, size and longevity of the tag used (Lucas \& Baras, 2001). Telemetry has recently been used to great effect in partial migration research to study phenotypic differences between migrants and residents, i.e. which individuals stay and which migrate (Brodersen et al., 2008a; Skov et al., 2011, Chapman et al., 2011c). Telemetry can be divided into active and passive telemetry where in the former the fishes are actively tracked whereas in passive telemetry data are collected from stationary (passive) listening stations. Whilst active telemetry has the obvious advantage of providing researchers with a fine-scale individual track of changes in location, this is not always necessary in partial migration studies to assess whether a fish is a migrant or resident. For fishes that migrate via distinct migratory corridors [for example up streams as many cyprinids do in the winter migration (Skov et al., 2008)], passive telemetry can provide information upon which individuals migrate and hence which individuals remain resident, in addition to timing and migratory destination. Passive telemetry is more suited 
for studies that require a high sample size due to the high effort involved in active telemetry work. Passive telemetry can also be used in more open systems (e.g. lakes or lagoons) where listening stations can be placed on buoys and individuals' positions can be estimated from multiple records of the same tag at different stations. These kind of set-ups, however, pose a greater logistical and financial challenge than stations placed in small streams. Choosing whether to use active or passive telemetry depends not only on the system but also upon the question. For example, passive telemetry would be suitable for investigations into the proportion of migratory fishes, or between year comparisons of individual migratory consistency or timing. If how migrants and residents use habitat during the non-migratory period in a lake is of interest, or estimating individual survival probabilities of migration $v$. residency or active telemetry would be potentially more suitable. A combination of the two methods can prove very effective, since one method complements the other (Brodersen et al. 2008b), but unfortunately this approach is rarely used.

The types of electronic tags available differ, and can be with or without internal power supply (batteries), and can be based on radiofrequency or acoustic signals. Normally the size of the tag is determined by the size of the battery which in turn strongly influences tag longevity, meaning that longitudinal studies normally require relatively large tags. Consequently many studies have focused on larger and older individuals whereas telemetry studies of small individuals are scarce. This may mask patterns of age or size-specific partial migration, and also potentially lead to an underestimation of the prevalence of partial migration in species of smaller body size. The smallest telemetry tags available are passive integrated transponder tags (PIT tags) which can be as small as $8 \mathrm{~mm}$ long with a mass $<0.03 \mathrm{~g}$. PIT tags have no internal battery but are energized when close to special reader units which create electromagnetic fields. The miniature PIT tags are advantageous compared to the larger tags with batteries as they are much cheaper and can be used in smaller fishes but their use is restricted to systems where migrating fishes pass a confined area (Aarestrup et al., 2003; Skov et al., 2008).

Another type of tag that could be used in studies of partial migration is an archival or data storage tag (DST). These tags sample information about one or several different environmental signals in the vicinity of the tagged fish, such as conductivity, temperature, oxygen, pressure (depth), light intensity or salinity (Neuenfeld et al., 2007; Aarestrup et al., 2009; Reddin et al., 2011), from which it is potentially possible to geolocate the fishes and consequently determine differences in migration patterns and habitat preferences between individuals (Pedersen et al., 2008; Neuenfeld et al., 2007). This technique has mostly been used in marine environments, where variations in environmental signals allow relatively accurate geolocation. DST tags can also sample internal physiological information from the fish such as heart rate and electro cardiograms (Muramoto et al., 2004), muscle activity (Quintella et al., 2004), acceleration (Nakamura et al., 2011), or a combination of these (Clark et al., 2010), which could be used to shed light on (for example) the energetic costs of migration $v$. residency. DST tags are most often dependent on being retrieved from the tagged fish, which can be a challenge. In its simplest form, data retrieval from the DST tags requires recaptures of the fish (Neuenfeld et al., 2007). Alternatives to this are pop-up tags which are DST tags that include devices which allow the tag to pop off the fish at some pre-programmed time and float to the surface, where data are uploaded via satellite (Aarestrup et al., 2009). Tags have also been developed 
that can recognize and store information about other tagged individuals within a certain proximity [proximity tags (Guttridge et al., 2010)]. These tags have great potential to study social structure and partial migration, and answer questions about the importance of social interactions in migratory behaviour, and about how migrants and residents interact during the non-migratory period.

A final direct technique that has recently been utilized with great success to study partial DVM is hydroacoustic technology. Hydroacoustic techniques provide a useful technique to monitor the spatial distribution and migration of fish populations and is based on equipment that directs acoustic beams either vertically (Busch \& Mehner, 2009) or horizontally in the water. When the acoustic energy hits an object in the water, such as schools of fishes or even individual fish, some of the energy is backscattered to the equipment, called transducers, and converted into a quantifiable electrical signal (Lucas \& Baras, 2001). In a recent study, Mehner \& Kasprzak (2011) used this technology to demonstrate that Coregenous spp. perform partial DVM in a German lake.

\section{INDIRECT TECHNIQUES TO STUDY PARTIAL MIGRATION}

The use of indirect techniques to study partial migration has also undergone somewhat of a revolution in recent years. Techniques such as otolith microchemistry, stable isotope and molecular (e.g. microsatellite) analysis have proliferated and provided many useful insights into migratory behaviour in fishes. Indirect techniques have many benefits over direct techniques, such as active tracking of fishes. For example using otolith microchemistry the migratory history of an individual fish over its entire lifetime (Secor, 2010) can be potentially viewed. Here, each method is briefly described and an example of its utility in partial migration research given.

Otolith microchemistry based on either trace element ratios (often $\mathrm{Sr}$ :Ca ratios) or stable isotopes has frequently been used to establish the migration history of different individuals within a population (Gillanders, 2005). For example, Sr:Ca ratios were used to establish the occurrence of partial breeding migration in E. lucius from the Baltic Sea where a contingent migrates to spawn in freshwater areas whereas others remain resident to spawn in the saline environment [breeding partial migration (Engstedt et al., 2011)]. This technique is particularly suited to studies of partial anadromy and catadromy, where freshwater and marine microchemical signatures are highly divergent (Tsukamoto et al., 1998). In addition to their chemical composition, otoliths can also carry useful information in the shape of their annuli. A recent study showed that the shape of the juvenile portion of $C$. harengus otoliths could be used to differentiate between migrants and residents with 95\% accuracy (Burke et al., 2008). Likewise, migratory and resident individuals in a population can be potentially distinguished from each other based on isotopic signatures sampled from soft tissue samples. The stable-isotope approach is based on the fact that food-web isotopic signatures are reflected in the tissues of organisms. Since isotopic signatures can vary spatially, based on a variety of biogeochemical processes, organisms moving between isotopically distinct food webs can carry with them information on the location of previous feeding (Hobson, 1999). In addition to their chemical composition, otoliths can also carry useful information in the shape of their annuli.

Partial migration can also be investigated with molecular genetic analyses such as microsatellite and restriction site associated DNA (RAD) sequencing techniques. 
These may be especially useful for assessing breeding partial migration in which population genetic techniques could test whether migrants and residents spawn in geographically distinct areas (microsatellites), or potentially identifying genomic regions linked to migratory behaviour (RAD sequencing). Finally, parasite prevalence can also be used as an indirect indicator of varying migratory behaviour within populations, as migrants will potentially be exposed to parasites on the migratory grounds that residents do not encounter. For example, a study investigating $C$. harengus distinguished between individuals from two spawning populations using a comparison of endoparasites on fish (Campbell et al., 2007).

\section{CONCLUDING REMARKS}

This review suggests that partial migration is much more widespread amongst fishes than previously thought (Jonsson \& Jonsson, 1993). Many species from a diverse series of orders partially migrate, and the true taxonomic distribution of this migratory mode is likely to be even broader than is reported here due to geographic and taxonomic gaps in the literature. One of the problems encountered when synthesizing the growing literature on partial migration in fishes was of the varied terminology adopted to describe migratory variation. Following earlier discussions of this issue (Secor \& Kerr 2009) here an attempt has been made to clarify definitions and types of partial migration. It is hoped that the term partial migration will become the accepted term amongst ichthyologists of different backgrounds and research foci. In this way the understanding of this fascinating phenomenon, both among fish biologists and also more widely, can be promoted. Finally, many of the techniques now in use to help scientists find answers to the puzzle of partial migration have been outlined. It is hoped that this review will stimulate innovative and exciting future research projects, and inspire ichthyologists to apply partial migration thinking to their own studies of the movement and ecology of fishes.

We thank J.-M. Fromentin for interesting discussions regarding ABFT migration, and K. Aarestrup for fruitful conversations about methodology. Thanks to A. Shaw for allowing us to include her excellent figure to illustrate the types of partial migration. B.B.C. received support from a European Commission (FP7) Marie Curie Intra-European Fellowship grant and the Centre for Animal Movement Research (CAnMove, which is financed by a Linnaeus grant (349-2007-8690) from the Swedish Research Council and Lund University). C.S. is funded by the Danish Angling Licence funds. Finally, our thanks go out to J. Metcalfe for putting together this excellent themed issue and for the invitation to submit, and to J. Metcalfe and J. Craig for helpful and understanding editing of our sister reviews.

\section{References}

Aarestrup, K., Lucas, M. C. \& Hansen, J. A. (2003). Efficiency of a nature-like bypass channel for sea trout (Salmo trutta) ascending a small Danish stream studied by PIT telemetry. Ecology of Freshwater Fishes 12, 160-168.

Aarestrup, K., Økland, F., Hansen, M. M., Righton, D., Gargan, P., Castonguay, M., Bernatchez, L., Howey, P., Sparholt, H., Pedersen, M. I. \& McKinley, R. S. (2009). Oceanic spawning migration of the European eel (Anguilla anguilla). Science 325, 1660 . 
Arai, T., Hayano, H., Asami, H. \& Miyazaki, N. (2003). Coexistence of anadromous and lacustrine life histories of the shiraou, Salangichthys microdon. Fisheries Oceanography 12, 134-139.

Arai, T., Yang, J. \& Miyazaki, N. (2006). Migration flexibility between freshwater and marine habitats of the pond smelt Hypomesus nipponensis. Journal of Fish Biology 68, $1388-1398$.

Baker, R. R. (1978). The Evolutionary Ecology of Animal Migration. London: Hodder \& Stoughton.

Beamish, R. J. \& McFarlane, G. A. (1988). Resident and dispersal behaviour of adult sablefish in the slope waters off Canada's west coast. Canadian Journal of Fisheries and Aquatic Sciences 45, 152-164.

Beaumont, W. R. C. \& Mann, R. H. K. (1984). The age, growth and diet of a freshwater population of the flounder Platichthys flesus (L.), in southern England. Journal of Fish Biology 25, 607-616.

Bell, J. D., Lyle, J. M., Bulman, C. M., Graham, K. J., Newton, G. M. \& Smith, D. C. (1992). Spatial variation in reproduction, and occurrence of non-reproductive adults, in orange roughy, Hoplostethus atlanticus Collett (Trachichthyidae), from south-eastern Australia. Journal of Fish Biology 40, 107-122.

Block, B. A., Teo, S. L., Walli, A., Boustany, A., Stokesbury, M. J., Farwell, C. J., Weng, K. C., Dewar, H. \& Williams, T. D. (2005). Electronic tagging and population structure of Atlantic bluefin tuna. Nature 434, 1121-1127.

Bohlin, T., Pettersson, J. \& Degerman, E. (2001). Population density of migratory and resident brown trout Salmo trutta in relation to altitude: evidence for a migration cost. Journal of Animal Ecology 70, 112-121.

Boyle, W. A. (2011). Short-distance partial migration of Neotropical birds: a community-level test of the foraging limitation hypothesis. Oikos 120, 1803-1816.

Brodersen, J., Nilsson, P. A., Hansson, L.-A., Skov, C. \& Brönmark, C. (2008a). Conditiondependent individual decision-making determines cyprinid partial migration. Ecology 89, $1195-1200$.

Brodersen, J., Nilsson, P. A., Ammitzbøll, J., Hansson, L.-A., Skov, C. \& Brönmark, C. $(2008 b)$. Optimal swimming speed in head currents and effects on distance movement of winter-migrating fish. PloS One 3, e2156.

Brodersen, J., Nicolle, A., Nilsson, P. A., Skov, C., Brönmark, C. \& Hansson, L.-A. (2011). Interplay between temperature, fish partial migration and trophic dynamics. Oikos 120, $1838-1846$.

Brodersen, J., Nilsson, P. A., Chapman, B. B., Skov, C., Hansson, L.-A. \& Brönmark, C. (2012). Variable individual consistency in timing and destination of winter migrating fish. Biology Letters 8, 21-23.

Brönmark, C., Skov, C., Brodersen, J., Nilsson, P. A. \& Hansson, L.-A. (2008). Seasonal migration determined by a trade-off between predator avoidance and growth. PLoS One 3, e1957.

Brönmark, C., Brodersen, J., Chapman, B. B., Nicolle, A., Nilsson, P. A., Skov, C. \& Hansson, L.-A. (2010). Regime shifts in shallow lakes: the importance of seasonal fish migrations. Hydrobiologia 646, 91-100.

Burke, N., Brophy, D. \& King, P. A. (2008). Shape analysis of otolith annuli in Atlantic herring Clupea harengus: a new method for tracking fish populations. Fisheries Research 91, 133-143.

Busch, S. \& Mehner, T. (2009). Hydroacoustic estimates of fish population depths and densities at increasingly longer time scales. International Review of Hydrobiology 94, $91-102$.

Cagnacci, F., Focardi, S., Heurich, M., Hewison, A. J. M., Morellet, N., Kjellander, P., Linnell, J. D. C., Neteler, M., Delucchi, L. \& Ossi, F. (2011). Partial migration in roe deer: migratory and resident tactics are end points of a behavioural gradient determined by ecological factors. Oikos 120, 1790-1802.

Campana, S. E., Joyce, W. \& Kukla, D. W. (2009). Growth and reproduction of spiny dogfish off the eastern coast of Canada, including inferences on stock structure. In Biology and Management of Dogfish Sharks (Gallucci, V. F., McFarlane, G. A. \& Bargmann, G. G., eds), pp. 195-208. Bethesda, MD: American Fisheries Society. 
Campbell, N., Cross, M. A., Chubb, J. C., Cunningham, C. O., Hatfield, E. M. C. \& MacKenzie, K. (2007). Spatial and temporal variations in parasite prevalence and infracommunity structure in herring (Clupea harengus L.) caught to the west of the British Isles and in the North and Baltic Seas: implications for fisheries science. Journal of Helminthology 81, 137-146.

Chapman, B. B., Brönmark, C., Nilsson, J.-Å. \& Hansson, L.-A. (2011a). Partial migration: an introduction. Oikos 120, 1761-1763.

Chapman, B. B., Brönmark, C., Nilsson, J.-Å. \& Hansson, L.-A. (2011b). The ecology and evolution of partial migration. Oikos 120, 1764-1775.

Chapman, B. B., Hulthén, K., Blomqvist, D. R., Hansson, L.-A., Nilsson, J.-Å., Brodersen, J., Nilsson, P. A., Skov, C. \& Brönmark, C. (2011c). To boldly go: Individual differences in boldness influence migratory tendency in a cyprinid fish. Ecology Letters 14, $871-876$.

Chapman, B. B., Hulthen, K., Brodersen, J., Nilsson, P. A., Skov, C., Hansson, L.-A. \& Brönmark, C. (2012). Partial migration in fishes: causes and consequences. Journal of Fish Biology 81, 456-478. DOI: 10.1111/j.1095-8649.2012.03342.x

Chino, N. \& Arai, T. (2010). Habitat use and habitat transitions in the tropical eel Anguilla bicolor bicolor. Environmental Biology of Fishes 89, 571-578.

Clark, T. D., Sandblom, E., Hinch, S. G., Patterson, D. A., Frappell, P. B. \& Farrell, A. P. (2010). Simultaneous biologging of heart rate and acceleration, and their relationships with energy expenditure in free-swimming sockeye salmon (Oncorhynchus nerka). Journal of Comparative Physiology 180, 673-684.

Comeau, L. A., Campana, S. E. \& Castonguay, M. (2002). Automated monitoring of a largescale cod Gadus morhua migration in the open sea. Canadian Journal of Fisheries and Aquatic Sciences 59, 1845-1850.

Cote, D., Moulton, S., Frampton, P. C. B., Scruton, D. A. \& McKinley, R. S. (2004). Habitat use and early winter movements by juvenile Atlantic cod in a coastal area of Newfoundland. Journal of Fish Biology 64, 665-679.

Dadswell, M. J. (1979). Biology and population characteristics of the shortnose sturgeon, Acipenser brevirostrum LeSueur 1818 (Osteichthyes: Acipenseridae) in the Saint John River estuary, New Brunswick, Canada. Canadian Journal of Zoology 57, 2186-2210.

Daverat, F., Limburg, K. E., Thibault, I., Shiao, J. C., Dodson, J. J., Caron, F., Tzeung, W. N., Iizuka, Y. \& Wickstrom, H. (2006). Phenotypic plasticity of habitat use by 3 temperate eel species, Anguilla anguilla, A. japonica and A. rostrata. Marine Ecology Progress Series 308, 231-241.

Dingle, H. (1996). Migration: The Biology of Life on the Move. Oxford: Oxford University Press.

Dunn, M. R. \& Pawson, M. G. (2002). The stock structure and migrations of plaice populations on the west coast of England and Wales. Journal of Fish Biology 61, 360-393.

Durbec, M., Cavalli, L., Grey, J., Chappaz, R. \& Nguyen The, B. (2010). The use of stable isotopes to trace small-scale movements by small fish species. Hydrobiologia 641, $23-31$.

Engelhard, G. H. \& Heino, M. (2005). Scale analysis suggests frequent skipping of the second reproductive season in Atlantic herring. Biology Letters 1, 172-175.

Engstedt, O., Stenroth, P., Larsson, P., Ljunggren, L. \& Elfman, M. (2011). Assessment of natal origin of pike Esox lucius in the Baltic Sea using Sr:Ca in otoliths. Environmental Biology of Fishes 89, 547-555.

Espanhol, R., Almeida, P. R. \& Alves, M. J. (2007). Evolutionary history of lamprey paired species Lampetra fluviatilis (L.) and Lampetra planeri (Bloch) as inferred from mitochondrial DNA variation. Molecular Ecology 16, 1909-1924.

Fukumori, K., Okuda, N., Hamaoka, H., Fukumoto, T., Takahashi, D. \& Omori, K. (2008). Stable isotopes reveal life history polymorphism in the coastal fish Apogon notatus. Marine Ecology Progress Series 362, 279-289.

Gillanders, B. W. (2005). Otolith chemistry to determine movements of diadromous and freshwater fish. Aquatic Living Resources 18, 291-300.

Godinho, A. L. \& Kynard, B. (2006). Migration and spawning of radio-tagged zulega in a dammed Brazilian river. Transactions of the American Fisheries Society 135, 811-824. 
Godinho, A. L., Kynard, B. \& Godinho, H. (2007). Migration and spawning of female surubim in the Sao Paulo river. Environmental Biology of Fishes 80, 421-433.

Goto, A. \& Arai, T. (2003). Migratory histories of three types of Cottus pollux (small-egg, middle-egg, and large-egg types) as revealed by otolith microchemistry. Ichthyological Research 50, 67-72.

Grayson, K. L., Bailey, L. L. \& Wilbur, H. M. (2011). Life history benefits of residency in a partially migrating pond-breeding amphibian. Ecology 92, 1236-1246.

Guttridge, T. L., Gruber, S. H., Krause, J. \& Sims, D. W. (2010). Novel acoustic technology for studying free-ranging shark social behaviour by recording individuals' interactions. PLOS ONE 5, e9324.

Hansson, L.-A. \& Hylander, S. (2009). Size-structured risk assessments govern Daphnia migration. Proceedings of the Royal Society B 276, 331-336.

Hansson, L.-A., Nicolle, A., Brodersen, J., Romare, P., Nilsson, P. A., Brönmark, C. \& Skov, C. (2007). Consequences of fish predation, migration, and juvenile ontogeny on zooplankton spring dynamics. Limnology and Oceanography 52, 696-706.

Hardisty, M. W. (1986). General introduction to lampreys. In The Freshwater Fishes of Europe, Vol. 1 (Holcík, J, ed), pp. 19-83. Wiesbaden: Aula-Verlag.

Hendry, A. P., Bohlin, T., Jonsson, B. \& Berg, O. (2004). To sea or not to sea: anadromy versus non-anadromy in salmonids. In Evolution Illuminated: Salmon and their Relatives (Hendry, A. P. \& Stearns, S. C., eds), pp. 92-125. Oxford: Oxford University Press.

Hicks, B. J., West, D. W., Barry, B. J., Markwitz, A., Baker, C. F. \& Mitchell, C. P. (2005). Chronosequences of strontium in the otoliths of two New Zealand migratory freshwater fish, Inanga (Galaxias maculatus) and Koaro (G. brevipinnis). International Journal of PIXE 15, 95-101.

Higuchi, M., Goto, A. \& Yamakazi, F. (1996). Genetic structure of threespine stickleback, Gasterosteus aculeatus, in Lake Harutori, Japan, with reference to coexisting anadromous and freshwater forms. Ichthyological Research 43, 349-358.

Hobson, K. A. (1999). Tracing origins and migration of wildlife using stable isotopes: a review. Oecologia 150, 314-326.

Iles, T. D. \& Sinclair, M. (1982). Atlantic herring: stock discreteness and abundance. Science 215, 627-633.

Jensen, O. P., Hansson, S., Didrikas, T., Stockwell, J. D., Hrabik, T. R., Axenrot, T. \& Kitchell, J. F. (2011). Foraging, bioenergetic and predation constraints on diel vertical migration: field observations and modelling of reverse migration by young-of-the-year herring Clupea harengus. Journal of Fish Biology 78, 449-465.

Jepsen, N. \& Berg, S. (2002). The use of winter refuges by roach tagged with miniature radio transmitters. Hydrobiologia 483, 167-173.

Jonsson, B. \& Jonsson, N. (1993). Partial migration: niche shift versus sexual maturation in fishes. Reviews of Fish Biology and Fisheries 3, 348-365.

Kedney, G. I., Boulé, V. \& Fitzgerald, G. J. (1987). The reproductive ecology of three-spine sticklebacks breeding in fresh and brackish water. American Fisheries Society Symposium 1, 151-161.

Kerr, L. A. \& Secor, D. H. (2010). Latent effects of early life history on partial migration for an estuarine-dependent fish. Environmental Biology of Fishes 89, 479-492.

Kerr, L. A. \& Secor, D. H. (2011). Partial migration across populations of white perch Morone americana: a flexible life history strategy in a variable estuarine environment. Estuaries and Coasts 35, 1-10.

Kerr, L. A., Secor, D. H. \& Piccoli, P. M. (2009). Partial migration of fishes as exemplified by the estuarine-dependent white perch. Fisheries 34, 114-123.

Kitamura, T., Kume, M., Takahashi, H. \& Goto, A. (2006). Juvenile bimodal length distribution and sea-run migration of the lower modal group in the Pacific Ocean form of the three-spined stickleback. Journal of Fish Biology 69, 1245-1250.

Limburg, K. E., Blackburn, I., Schmidt, R., Lake, T., Hasse, J., Elfman, M. \& Kristiansson, P. (2001). Otolith microchemistry indicates unexpected patterns of residency and anadromy in blueback herring, Alosa aestivalis, in the Hudson and Mohawk rivers. Bulletin Francais de la Peche et de la Pisciculture 362, 931-938.

Lucas, M. C. \& Baras, E. (2001). Migration of Freshwater Fishes. Oxford: Blackwell Science. 
McFarlane, G. A. \& King, J. R. (2003). Migration patterns of spiny dogfish (Squalus acanthias) in the North Pacific Ocean. Fisheries Bulletin 101, 358-367.

McPhee, M. V., Utter, F., Stanford, J. A., Kuzishchin, K. V., Savvaitova, K. A., Pavlov, D. S. \& Allendorf, F. W. (2007). Population structure and partial anadromy in Oncorhynchus mykiss from Kamchatka: relevance for conservation strategies around the Pacific Rim. Ecology of Freshwater Fish 16, 539-547.

Mehner, T. \& Kasprzak, P. (2011). Partial diel vertical migrations in pelagic fish. Journal of Animal Ecology 80, 761-770.

Muramoto, H., Ogawa, M., Suzuki, M. \& Naito, Y. (2004). Little Leonardo digital data logger: its past, present and future role in bio-logging science. Memoirs of National Institute of Polar Research (Special Issue) 58, 196-202.

Nakamura, I., Watanabe, Y. Y., Papastamatiou, Y. P., Sato, K. \& Meier, C. G. (2011). Yoyo vertical movements suggest a foraging strategy for tiger sharks Galeocerdo cuvier. Marine Ecology Progress Series 424, 237-246.

Näslund, I., Milbrink, G., Eriksson, L. O. \& Holmgren, S. (1993). Importance of habitat productivity differences, competition and predation for the migratory behaviour of Arctic charr. Oikos 66, 538-546.

Neuenfeld, S., Hinrichsen, H.-H., Nielsen, A. \& Andersen, K. H. (2007). Reconstructing migrations of individual cod (Gadus morhua L.) in the Baltic Sea by using electronic data storage tags. Fisheries Oceanography 16, 526-535.

Neverman, D. \& Wurtsbaugh, W. A. (1994). The thermoregulatory function of diel vertical migration for a juvenile fish, Cottus extensus. Oecologia 98, 247-256.

Newton, I. (2008). Migration Ecology of Birds. London: Academic Press.

Northcote, T. G. \& Ward, F. J. (1984). Lake resident and migratory smelt, Retropinna retropinna, of the lower Waikato River system, New Zealand. Journal of Fish Biology 27, 113-129.

Northcote, T. G., Hendry, C. H., Nelson, C. S. \& Boubee, J. A. T. (1992). Tests for migratory history of the New Zealand common smelt using otolith isotopic composition. Ecology of Freshwater Fishes 1, 61-72.

Olsen, A. (1954). The Biology, Migration, and Growth Rate of the School Shark, Galeorhinus australis (Macleay)(Carcharhanidae) in the South-eastern Australian Waters. Marine and Freshwater Research 5, 353-410.

Olsson, I. C. \& Greenburg, L. A. (2004). Partial migration in a landlocked brown trout population. Journal of Fish Biology 65, 106-121.

Olsson, I. C., Greenberg, L. A., Bergman, E. \& Wysujack, K. (2006). Environmentally induced migration: the importance of food. Ecology Letters 9, 645-651.

Paramore, L. M. \& Rulifson, R. A. (2001). Dorsal coloration as an indicator of different life history patterns for striped bass within a single watershed of Atlantic Canada. Transactions of the American Fisheries Society 130, 663-674.

Pearcy, W. G., Lorz, H. V. \& Peterson, W. (1979). Comparison of the feeding habits of migratory and non-migratory Stenobrachius leucopsarus (Myctophidae). Marine Biology 51, 1-8.

Pearse, D. E., Hayes, S. A., Bond, M. H., Hanson, C. V., Anderson, E. C., MacFarlane, R. B. \& Garza, J. C. (2009). Over the falls? Rapid evolution of ecotypic differentiation in steelhead/rainbow trout (Oncorhynchus mykiss). Journal of Heredity 100, 515-525

Pedersen, M. W., Righton, D., Thygesen, U. H., Andersen, K. H. \& Madsen, H. (2008). Geolocation of North Sea cod (Gadus morhua) using hidden Markov models and behavioural switching. Canadian Journal of Fisheries and Aquatic Sciences 65, 2367-2377.

Quinn, T. P. \& Brodeur, R. D. (1991). Intra-specific variations in the movement patterns of marine animals. American Zoologist 31, 231-241.

Quintella, B. R., Andrade, N. O., Koed, A. \& Almeida, P. R. (2004). Behavioural patterns of sea lampreys' spawning migration through difficult passage areas, studied by electromyogram telemetry. Journal of Fish Biology 65, 961-972.

Reddin, D. G., Downton, P., Fleming, I. A., Hansen, L. P. \& Mahon, A. (2011). Behavioural ecology at sea of Atlantic salmon (Salmo salar L.) kelts from a Newfoundland (Canada) river. Fisheries Oceanography 20, 174-191. 
Rideout, R. M., Rose, G. A. \& Burton, M. P. M. (2005). Skipped spawning in female iteroparous fishes. Fish and Fisheries 6, 50-72.

Rubenstein, D. R. \& Hobson, K. A. (2004). From birds to butterflies: animal movement patterns and stable isotopes. Trends in Ecology and Evolution 19, 256-263.

Ruzzante, D. E., Mariani, S., Bekkevold, D., Andre, C., Mosegaard, H., Clausen, L. A. W., Dahlgren, T. G., Hutchinson, W. F., Hatfield, E. M. C., Torstensen, E., Brigham, J., Simmonds, E. J., Laikre, L., Larsson, L. C., Stet, R. J. M., Ryman, N. \& Carvalho, G. (2006). Biocomplexity in a highly migratory pelagic marine fish, Atlantic herring. Proceedings of the Royal Society B 273, 1459-1464.

Saldana, J. \& Venables, B. (1983). Energy compartmentalisation in a migratory fish, Prochilodus mariae, of the Orinoco river. Copeia 1983, 617-623.

Salewski, V. (2003). Satellite species in lampreys: a worldwide trend for ecological speciation in sympatry? Journal of Fish Biology 63, 267-279.

Schaffer, W. M. \& Elson, P. F. (1975). The adaptive significance of variations in life history among local populations of Atlantic salmon in North America. Ecology 56, 577-590.

Schreiber, A. \& Engelhorn, R. (1998). Population genetics of a cyclostome species pair, river lamprey (Lampetra fluviatilis L.) and brook lamprey (Lampetra planeri Bloch). Journal of Zoological Systematics and Evolutionary Research 36, 85-99.

Secor, D. H. (1999). Specifying divergent migrations in the concept of stock: the contingent hypothesis. Fisheries Research 43, 13-34.

Secor, D. H. (2010). Is otolith science transformative? New views on fish migration. Environmental Biology of Fishes 89, 209-220.

Secor, D. H. \& Kerr, L. A. (2009). Lexicon of life cycle diversity in diadromous and other fishes. American Fisheries Society Symposium 69, 537-556.

Secor, D. H., Rooker, J. R., Zlokovitz, E. \& Zdanowicz, V. S. (2001). Identification of riverine, estuarine, and coastal contingents of Hudson River striped bass based upon otolith elemental fingerprints. Marine Ecology Progress Series 211, 245-253.

Sella, M. (1930). Distribution and migrations of the tuna (Thunnus thynnus L.) studied by the method of hooks, and other observations. Internationale Revue der gesamten Hydrobiologie und Hydrographie 24, 446-466.

Shaw, A. K. \& Levin, S. A. (2011). To breed or not to breed: a model of partial migration. Oikos 120, 1871-1879.

Sherwood, G. D. \& Grabowski, J. H. (2010). Exploring the life-history implications of colour variation in offshore Gulf of Maine cod Gadus morhua. ICES Journal of Marine Sciences 67, 1640-1649.

Skov, C., Brodersen, J., Nilsson, P. A., Hansson, L.-A. \& Brönmark, C. (2008). Inter- and size-specific patterns of fish seasonal migration between a shallow lake and its streams. Ecology of Freshwater Fish 17, 406-415.

Skov, C., Aarestrup, K., Baktoft, H., Brodersen, J., Brönmark, C., Hansson, L.-A., Nielsen, E. E., Nielsen, T. \& Nilsson, P. A. (2010). Influences of environmental cues, migration history and habitat familiarity on partial migration. Behavioral Ecology 21, 1140-1146.

Skov, C., Baktoft, H., Brodersen, J., Brönmark, C., Chapman, B. B., Hansson, L.-A. \& Nilsson, P. A. (2011). Sizing up your enemy: individual predation vulnerability predicts migratory probability. Proceedings of the Royal Society B 278, 1414-1418.

Smith, T. I. J. (1985). The fishery, biology and management of Atlantic sturgeon, Acipenser oxyrhynchus, in North America. Environmental Biology of Fishes 14, 61-72.

Thorson, T. B. (1971). Movements of bull sharks, Carcharhinus leucas, between Caribbean Sea and Lake Nicaragua demonstrated by tagging. Copeia 1971, 336-338.

Tsukamoto, K., Nakai, I. \& Tesch, W. V. (1998). Do all freshwater eels migrate? Nature 396, 635.

Yang, J., Arai, T., Liu, H. \& Miyazaki, N. (2006). Environmental signature in the otolith elemental fingerprint of the tapertail anchovy, Colia mystus, from the Changjiang estuary, China. Journal of Applied Ichthyology 22, 459-462.

Zanandrea, G. (1959). Speciation among lampreys. Nature 184, 380. 